\title{
ESTAR TO SMOS: DEVELOPMENT OF INTERFEROMETRIC RADIOMETRY FOR REMOTE SENSING FROM SPACE
}

\author{
D.M. Le Vine \\ Goddard Space Flight Center, Greenbelt, MD 20771
}

\begin{abstract}
ESTAR is an L-band radiometer that employs synthesis (interferometry) to obtain resolution in the across track dimension. It was designed as an aircraft prototype to demonstrate the technology of aperture synthesis for remote sensing of the earth from space. ESTAR was successful in several soil moisture and ocean salinity remote sensing experiments and demonstrated the potential of aperture synthesis for remote sensing. Among the lessons learned during the development of ESTAR are the scene dependence of calibration, that RFI is a problem, and the robustness of noise injection for the zero spacing radiometer. ESTAR was the first step in a path toward realizing aperture synthesis technology in space (e.g. SMOS). ESTAR was followed by a new instrument, 2D-STAR, which employs synthesis in both dimensions. 2D-STAR was tested in 2002 and participated in the SMEX field campaigns in 2003 and 2004.
\end{abstract}

Index Terms - Microwave radiometry, Passive microwave remote sensing, L-band

\section{INTRODUCTION}

ESTAR was developed in the late 1980's at the Goddard Space Flight Center and University of Massachusetts, Amherst. It was developed as an aircraft prototype to demonstrate the technology of aperture synthesis for remote sensing of the earth. The initial focus was on remote sensing of soil moisture from space where the need for long wavelengths presents problems for spatial resolution. ESTAR is a hybrid of a real and a synthetic aperture radiometer operating in the radio astronomy window at 1.413 GHz. It employs "stick" antennas to achieve resolution along track and uses aperture synthesis to achieve resolution across track [1]. ESTAR has five sticks oriented with their long axis in the direction of motion (Figure 1). Each stick antenna consists of an array (row) of eight horizontally polarized dipoles. The stick antennas are spaced at integer multiples of a half-wavelength (about $10.5 \mathrm{~cm}$ ) with a maximum spacing of $7 \lambda / 2$. With this configuration it is possible to obtain seven unique baselines plus one at the zero spacing. The result is a synthesized beam with a width of about \pm 4 degrees at nadir in the cross track dimension.
Figure 2 shows the actual antenna array with the radome removed. The box contains the RF hardware (filters, amplifiers, mixers, etc) and is mounted beneath the aircraft (Figure 3 in [1]). The signal is mixed to IF and then sent to the correlator which is located in the aircraft cabin together with the computer controller, power supplies and data storage.

The principles of image reconstruction and calibration are outlined in [1] and [2]. Novel features of the instrument at the time of its development include the implementation of the zero spacing measurement using a noise injection radiometer with the correlator electronics (Figure 5 in [1]), and the image reconstruction using oversampled values of the impulse response and a pseudo-inverse of the resultant matrix [1].

\section{EXPERIENCE}

First images were reported in 1990 [3] over a section of the Delmarva Peninsula close to Goddard's Wallops Flight Facility where tests of the hardware were performed. Figure 3 is a composite of data collected in this area showing ESTAR brightness temperature superimposed on a map of the region [4]. One of the first "surprises" during these flights was the appearance of RFI in what is supposed to be a protected band of the spectrum for passive use only [5]. Airports were identified as one source of RFI, but others were not identified.

ESTAR participated in several field experiments to measure soil moisture. Notable were the flights at the Walnut Gulch Watershed in 1991[1,6] which demonstrated the response of the instrument to changes in soil moisture under controlled conditions and its ability to produce data of high scientific quality. ESTAR supported research on soil moisture at the Little Washita River Watershed in 1992 [7] and later supported research during the Southern Great Plains experiments $[8,9]$. In one sense, these experiments were technology demonstrations, showing that aperture synthesis for radiometers was viable for remote sensing of the Earth; But, the experiments also produced data to support the use of L-band for future remote sensing of soil moisture from space. During this time experiments were also conducted on remote sensing of sea surface salinity, including the Delaware Coastal Current Experiment [10]. 


\section{LESSONS LEARNED}

ESTAR was a prototype and its development was a research activity with a learning curve typical of doing things for the first time. Many changes to the hardware were made along the way, most associated with the realities of working on an aircraft at high altitude. Among the things learned during this development were:

RFI: ESTAR operates within the spectral window at $1.413 \mathrm{GHz}$ restricted to passive use only. Although there should be no transmission, RFI was common and it became clear that airports, and presumably air traffic control radar, were a common source of the RFI.

Calibration is scene dependent: The gain and offset parameters established for each baseline were found to depend on the scene. Scenes were classified as "water", "land" and "mixed" with different coefficients for each.

Noise Injection is stable: ESTAR used a variation of a noise injection radiometer for the zero spacing which proved to be very stable in the presence of temperature variations of the instrument [1].

A picture is worth a thousand words: Although the theory was clear, it was images such as in Figure 3 and the maps produced at the Walnut Gulch and Little Washita River watersheds $[1,6]$ and during the Southern Great Plains (SGP) experiments $[8,9]$ that convinced the remote sensing community.

\section{HISTORICAL PERSPECTIVE}

ESTAR was a "pathfinder" designed to demonstrate the technology of aperture synthesis for eventual application in space. As ESTAR demonstrated success, a road map for future instruments in space was developed. In the USA, proposals were submitted for HYDROSTAR, an ESTARlike instrument employing aperture synthesis in the cross track dimension [11]. HYDROSTAR is shown in its deployed configuration in Figure 4 . It consists of 16 waveguide sticks, spaced at integer multiples of $1 / 2$ wavelength, and operating at L-band. Other instruments of the ESTAR design (one dimensional synthesis) were also developed at $37 \mathrm{GHz}$ and $10 \mathrm{GHz}$ [11].

In Europe, proposals were made for an instrument using aperture synthesis in both dimensions which eventually became SMOS. It was assumed that HYDROSTAR would fly first. But HYDROSTAR was never funded and SMOS became the first such instrument in space!

ESTAR has been supplanted by 2D-STAR an instrument which does synthesis in both dimensions [12]. 2D-STAR uses a square array of dual polarized patch antennas. The patches are spaced $1 / 2$ wavelengths apart and operate at a center frequency of $1.413 \mathrm{GHz}$. The array is fully populated but only those elements in along the principle axes (i.e. a cross) are used in the synthesis. 2D-STAR was tested in 2002 in the same region of the Delmarva Peninsula used by ESTAR (Figure 2) and during the summers of 2003 and 2004 participated in the SMEX03 and SMEX04 soil moisture experiments. Results from the SMEX03 sites in Alabama and Georgia are presented in [12].

Although the research focus has shifted to 2D-STAR, ESTAR is still functional and recently participated in a passive/active technology experiment to evaluate a digital beam forming radar with an across track footprint similar to that of ESTAR.

\section{REFERENCES}

[1] D. M. Le Vine, A. J. Griffis, C.T. Swift and T.J. Jackson, "ESTAR: A Synthetic Aperture Microwave Radiometer for Remote Sensing Applications", Proc. IEEE , Vol 82 (\#12), pp. 1787-1801, December, 1994.

[2] C.T. Swift, D. M. Le Vine and C.S. Ruf, "Aperture Synthesis Concepts in Microwave Remote Sensing of the Earth", IEEE Trans. Microwave Theory \& Techniques, Vol 39 (\#12), pp 19311935, December, 1991.

[3[. D.M. Le Vine, M. Kao, A.B. Tanner, C.T. Swift and A. Girffis, "Initial Results in the Development of a Synthetic Aperutre Microwave Radiometer", IEEE Trans. Geoscience \& Remote Sensing, Vol 28, pp. 614-619, July, 1990.

[4] D.M. Le Vine, C.T. Swift and M. Haken, "Development of the Synthetic Aperture Microwave Radiometer, ESTAR", IEEE Trans. Geoscience \& Remote Sensing, Vol 39 (\#1), pp. 199-202, January, 2001.

[5] D. M. Le Vine and M. Haken, "RFI at L-band in Synthetic Aperture Radiometers", Proc. International Geoscience \& Remote Sensing Symposium (IGARSS), Toulouse, France, July, 2003, Vol 3,pp 1742-1744.

[6] T.J. Jackson, D. M. Le Vine, et al, "Soil Moisture and Rainfall Estimation Over a Semiarid Environment with the ESTAR Microwave Radiometer", IEEE Trans. Geoscience \& Remote Sensing, Vol 31 (\#4), pp 836 - 841, July, 1993.

[7] T. J. Jackson, et al, "Large Area Mapping of Soil Moisture Using the ESTAR Passive Microwave Radiometer in Washita-92", Remote Sensing Environment, Vol 53, pp 27-37, 1995.

[8] T.J. Jackson, et al, "Soil Moisture Mapping at Region Scales Using Microwave Radiometry: The Southern great Plains Hydrology Experiment", IEEE Trans. Geoscience \& Remote Sensing, Vol 37 (\#5), pp. 2136-2151, September, 1999.

[9] D.M. Le Vine, et al, "ESTAR Measurements during the Southern Great Plains Experiments (SGP99)", IEEE Trans. Geoscience \& Remote Sensing, Vol 39 (\#8), pp. 1680-1685, 2001. 
[10] D.M. Le Vine, M. Kao, R.W. Garvine and T. Sanders, "Remote Sensing of Ocean Salinity: Results from the Delaware Coastal Current Experiment", J. Atmospheric and Oceanic Technology, Vol 15, pp 1478-1484, December, 1988.

[11] D.M. Le Vine, "Synthetic Aperture Radiometer Systems", IEEE Trans. Microwave Theory \& Techniques, Vol 47 (\#12), pp 2238-2236, December, 1999.

[12] D.M. Le Vine, T.J. Jackson and M. Haken, "Initial Images of the Synthetic Aperture Radiometer 2D-STAR", IEEE Trans. Geoscience \& Remote Sensing, Vol 45 (\#11), pp. 3623-3632, November, 2007.

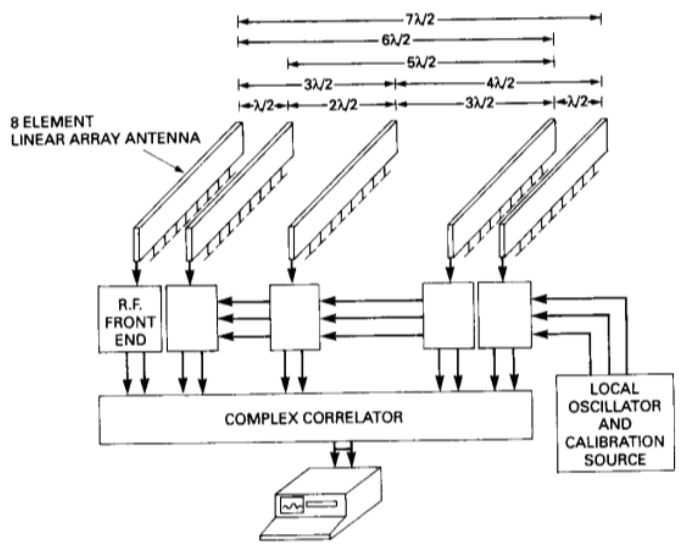

Figure 1: ESTAR configuration [1].

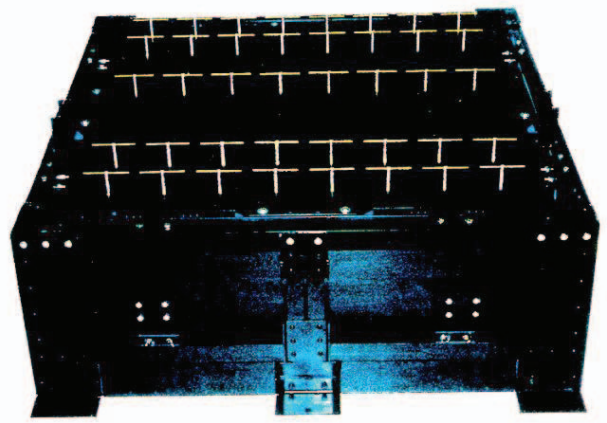

Figure 2: The ESTAR antenna array [1].

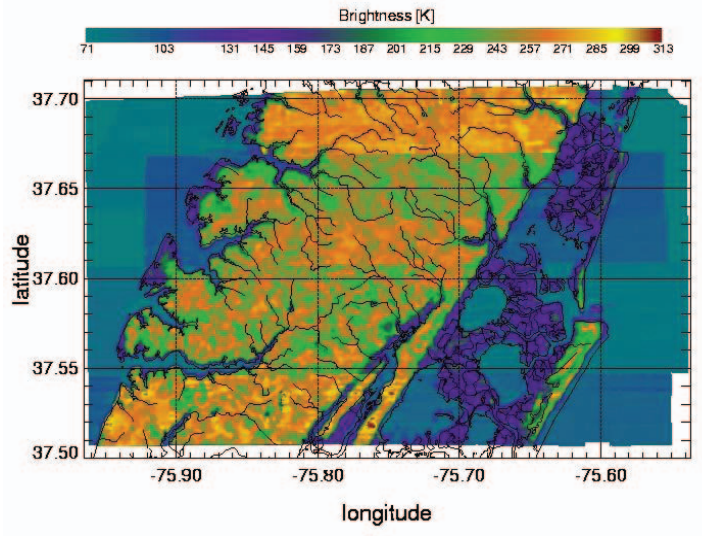

Figure 3: Composite of ESTAR images made during instrument testing [4]. The Chesapeake Bay is to the left and the Atlantic Ocean is to the right. The dark cool area is tidal marsh.

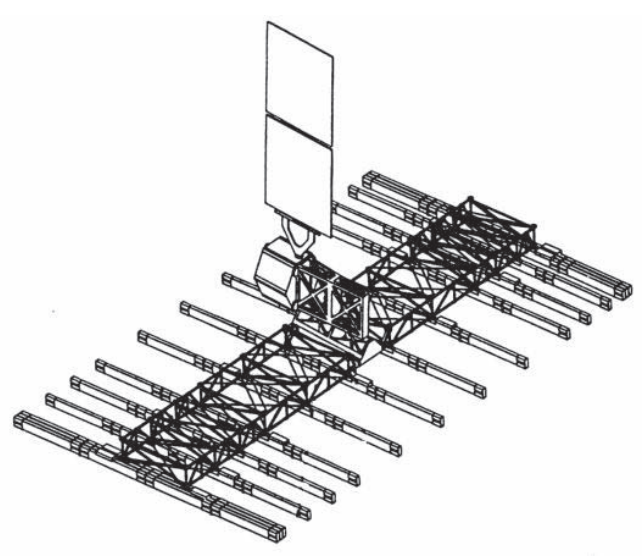

Figure 4: HYDROSTAR in its deployed configuration 11]. 